\title{
EFEITO DE DIFERENTES NÍVEIS DE CONTAGEM DE CÉLULAS SOMÁTICAS SOBRE A QUALIDADE DE LEITE FERMENTADO E QUEIJO MINAS FRESCAL
}

\author{
(Effect of different levels of somatic cells count on the quality of fermented milk and \\ Minas fresh cheese)
}

\section{'Lisiane Cristine Rincon de Lima, ${ }^{2}$ Luciano Soares de Lima, 'Bruna Moura Rodrigues, ${ }^{1 * B}$ Buna Barnei Saraiva, ${ }^{1}$ Magali Soares dos Santos Pozza}

\author{
'Departamento de Zootecnia, Universidade Estadual de Maringá, Maringá, Paraná, Brasil; \\ ${ }^{2}$ Departamento de Zootecnia, Universidade Federal de Minas Gerais, Belo Horizonte, Minas Gerais, \\ Brasil.
}

*E-mail para contato: bruna_9bs@hotmail.com

RESUMO - Este estudo foi desenvolvido com o objetivo de avaliar os efeitos de diferentes níveis de contagem de células somáticas (CCS) no leite sobre os parâmetros qualitativos de leite fermentado e queijo Minas Frescal. Foram coletadas amostras de leite de nove vacas, sendo os animais divididos em três grupos: baixa CSS $(<300.000 \mathrm{cel} / \mathrm{mL})$, média CCS $(300.000$ a $600.000 \mathrm{cel} / \mathrm{mL})$ e alta CCS $(>600.000 \mathrm{cel} / \mathrm{mL})$. Com o leite de cada grupo, foram produzidos leite fermentado e queijo Minas Frescal e estes foram avaliados durante 30 e 20 dias, respectivamente. $\mathrm{Na}$ avaliação sensorial, não foram observadas diferenças nos atributos avaliados em função dos diferentes níveis de CCS para o leite fermentado. No entanto, para o queijo Minas Frescal, apenas o produto elaborado a partir do leite contendo baixa e média CCS apresentaram os maiores escores medios para cor, sabor, textura, aparência e aceitação global. Para o leite fermentado, foram observadas interações significativas entre os tratamentos e o tempo $(P<0,05)$, para os parâmetros de coloração $b^{*}, \mathrm{pH}$ e sinérese, enquanto as interações observadas no queijo foram para os parâmetros de coloração $a^{*}, b^{*}, \mathrm{pH}$ e acidez. A qualidade do queijo Minas Frescal é influenciada negativamente quando a CCS do leite utilizado na produção é maior que $600.000 \mathrm{cel} / \mathrm{mL}$. Entretanto, o leite fermentado não sofre a mesma influência da CCS para a aceitação por consumidores.

Palavras-chave: aceitação sensorial, derivados lácteos, microbiologia, vida de prateleira.

ABSTRACT - This study was developed with the objective of evaluating the effects of different levels of somatic cell count (CCS) in milk on the qualitative parameters of fermented milk and Minas Frescal cheese. Milk samples were collected from nine cows, and the animals were divided into three groups: low CSS $(<300,000$ cell / mL), average CCS $(300,000$ to 600,000 cell $/ \mathrm{mL}$ ) and high CCS $(>600,000$ cell $/ \mathrm{mL})$. With the milk from each group, fermented milk and Minas Frescal cheese were produced and these were evaluated for 30 and 20 days, respectively. In the sensory evaluation, there were no differences in the attributes evaluated due to the different levels of CCS for fermented milk. However, for Minas Frescal cheese, only the product made from milk containing low and medium CCS had the highest average scores for color, flavor, texture, appearance and global acceptance. For fermented milk, significant interactions were observed between treatments and time $(P<0.05)$, for color parameters $\mathrm{b}^{*}, \mathrm{pH}$ and syneresis, whereas the interactions observed in cheese were for color parameters $\mathrm{a}^{*}, \mathrm{~b}^{*}, \mathrm{pH}$ and acidity. The quality of Minas Frescal cheese is negatively influenced when the CCS of the milk used in production 
is greater than 600,000 cell / $\mathrm{mL}$. However, fermented milk does not suffer the same influence as CCS for consumer acceptance.

Keywords: sensory acceptance, dairy products, microbiology, shelf life.

\section{INTRODUÇÃO}

A mastite é uma das doenças mais comuns e prejudiciais em rebanhos leiteiros e é definida como uma reação inflamatória ocorrida na glândula mamária, geralmente, em reposta à entrada de microrganismos patogênicos via orifício dos tetos e pode se manifestar de forma clínica ou subclínica (De Vliegher et al., 2012).

A ocorrência de mastite está diretamente relacionada com o aumento da contagem de células somáticas (CCS) no leite, podendo ocasionar mudanças na sua composição, como reduzida secreção de proteína, gordura e lactose, isso ocorre devido ação direta de patógenos ou de enzimas, prejudicando a qualidade e quantidade de leite produzido (Demeu et al. 2016; Costa et al. 2017; Silva e Antunes, 2018). Além da perda na produção diária, o leite com elevada CCS também causa prejuízos aos laticínios, pois os produtos derivados apresentam menor rendimento industrial e redução na vida de prateleira (Silva et al., 2010; Mesquita et al., 2018).

No Brasil, a instrução normativa ํo 76 de novembro de 2018 determina que o leite cru refrigerado deve apresentar médias geométricas trimestrais de CCS inferiores à 500.000 células $/ \mathrm{mL}$. Mas contagens de CCS acima dos valores estipulados pela legislação tem sido contatada por diversos autores no rebanho brasileiro (Machado et al., 2000; Carvalho et al., 2013).

Segundo Magalhães et al. (2006), a alta CCS não consiste em risco para a saúde do consumidor devido a destruição dos patógenos durante o processo de pasteurização, porém as enzimas microbianas não são destruídas neste processo, reduzindo a vida de prateleira dos produtos por provocarem a hidrólise de proteínas e lipídeos. Derivados lácteos com alto teor de umidade tais como leite fermentado e queijo Minas Frescal, parecem ser mais suscetíveis à atividade de enzimas microbianas (Samaržija et al., 2012). Assim, situações predisponentes a uma maior contaminação do leite devido à alta CCS, poderiam influenciar a qualidade dos derivados lácteos em suas características físico-químicas e sensoriais.

Desta forma, este trabalho foi realizado com objetivo de avaliar os efeitos de diferentes níveis de CCS no leite sobre as caraterísticas físico-químicas e qualidade sensorial em leite fermentado e queijo Minas Frescal ao longo de diferentes tempos de armazenamento.

\section{MATERIAL E MÉTODOS}

Foram coletadas amostras de leite de nove vacas da raça Holandês, previamente selecionadas conforme a CCS (média trimestral) do controle leiteiro do rebanho pertencente ao setor de bovinocultura de leite, da Fazenda Experimental de Iguatemi (FEI). Após a coleta, a CCS foi determinada utilizando equipamento AKSO, no Centro Mesorregional de Excelência e Tecnologia do Leite - FEl, pertencente à Universidade Estadual de Maringá (UEM). De posse destes resultados, os animais foram divididos em três grupos $(\mathrm{n}=3)$ : baixa CCS $(<300.000 \mathrm{cel} / \mathrm{Ml})$; média CCS $(300.000$ a $600.000 \mathrm{cel} / \mathrm{mL})$ e alta CCS $(>600.000 \mathrm{cel} / \mathrm{mL})$. Os tratamentos definidos foram superiores aos valores considerados na legislação vigente $($ IN 76, 2018) a fim de se verificar a influência de altos níveis de CCS sobre a produção de derivados lácteos. 


\section{Produção de derivados lácteos}

Para elaboração dos derivados lácteos, 9 litros de leite foram pasteurizados a $90^{\circ} \mathrm{C}$ por $3 \mathrm{~min}$, a fim de promover a desnaturação das proteínas do soro para a redução da contração do coágulo da caseína do iogurte, diminuindo, consequentemente, a sinérese, sendo esta pasteurização indicada para elaboração de leites fermentados (Da Silva Robazza et al., 2011; Oliveira et al., 2019). Em seguida, o leite fermentado foi produzido com fermento lácteo (Lactobacillus acidophilus $L A$ - 5, Bifidobacterium BB-12 e Streptococcus thermophilus) a $43^{\circ} \mathrm{C}(5$ $\mathrm{L} /$ tratamento). Após a fermentação, o produto foi mantido sob refrigeração para acidificação por $24 \mathrm{~h}$ para posterior quebra do gel e envase em garrafas de polietileno de $1 \mathrm{~L}$. As amostras de leite fermentado foram avaliadas nos tempos 1, 15 e 30 dias quanto à cor, $\mathrm{pH}$, acidez e sinérese.

A cor foi determinada pelo sistema CIELAB em equipamento Minolta® CR400 por meio dos parâmetros de cor: $L^{*}$ (luminosidade de 0 a 100), $a^{*}$ e $b^{*}$ (coordenadas de cromaticidade), sendo a variável $a^{*}$ relativa de verde ao vermelho e a variável $b^{*}$ relativa de azul ao amarelo. A avaliação do $\mathrm{pH}$ foi realizada em $\mathrm{pHmetro}$ digital, e a acidez, em termos de graus Dornic, foi determinada por titulação (Instituto Adolfo Lutz, 2008). A sinérese foi analisada pelo método de centrifugação (Robitaille et al., 2009) em que o leite fermentado $(25 \mathrm{~g})$ foi pesado em tubos falcon cônicos de $50 \mathrm{~mL}$ e centrifugado em estufa refrigerada a $500 \mathrm{rpm}$ por 10 minutos a $4^{\circ} \mathrm{C}$. A sinérese foi expressa em porcentagem de soro liberado na centrifugação. Todas as análises foram realizadas com três repetições e em triplicata.

O queijo Minas Frescal foi produzido a partir de $8 \mathrm{~L}$ de leite/tratamento sendo adicionado de cloreto de cálcio, cloreto de sódio e coalho conforme previamente registrado por Andreatta et al. (2009). Foram mantidos sob refrigeração e avaliados quanto à umidade, atividade de água e textura, logo após a elaboração. Para a atividade de água foi utilizado equipamento Novasina (LabSwift). O perfil de dureza foi avaliado segundo Rawson e Marshall (1997) em texturômetro universal, com probe cilíndrica de fundo chato de $35 \mathrm{~mm}$ de diâmetro (A/BE 35) e os resultados obtidos com auxílio do programa Texture Expert versão 1.11 para TPA (Texture Profile Analysis). As condições de medida foram padronizadas em calibre do probe $60 \mathrm{~mm}$, força de penetração de $15 \mathrm{~g}$ e velocidade de compressão de $3 \mathrm{~mm} . \mathrm{s}-1$.

Outros parâmetros também foram avaliados, como o pH, cor e acidez, mensurados em três tempos, sendo estes, dias 1, 10 e 20. As análises foram realizadas da mesma forma descrita anteriormente para o leite fermentado.

Os produtos lácteos produzidos também foram submetidos à avaliação sensorial por uma equipe de 40 provadores para leite fermentado e 50 provadores para queijo Minas Frescal, estes eram provadores não treinados considerados potenciais consumidores, alunos e funcionários da universidade, igualmente distribuídos de ambos os sexos e com faixa etária entre 25 a 50 anos. Os provadores avaliaram as amostras quanto a cor, sabor, textura, aparência e aceitação global, atribuindo notas numa escala hedônica de 1 a 9 pontos, em que 1 expressava desgostei muitíssimo e 9 gostei muitíssimo.

Os dados foram submetidos ao sistema de análises estatísticas SAEG (1999). As médias das triplicatas foram comparadas pelo teste Tukey a $5 \%$ de probabilidade.

\section{RESULTADOS E DISCUSSÃO}

Os efeitos dos níveis de CCS sobre a variável b* (relativa ao azul e amarelo), valores de $\mathrm{pH}$ e sinérese dos leites fermentados, foram diferentes ao longo dos dias 
de avaliação (Tabela 1). Todavia podemos dizer que a coloração do leite fermentado não foi influenciada pelos tratamentos, dada a falta de efeito sobre as variáveis $L^{*}$ (luminosidade) e $\mathrm{a}^{*}$ (relativa ao verde e vermelho), sugerindo que CCS exerce pouca influência sobre a coloração do leite fermentado. Aryana et al. (2007) afirmam que, mesmo que algumas alterações de cor sejam detectadas pelo instrumento de medida, muitas vezes estas alterações não são detectadas pelo olho humano. Isto é corroborado pela falta de efeito para o item cor durante a avaliação sensorial do leite fermentado (Tabela 4).

Houve interação significativa entre os fatores tratamento e tempo com relação ao $\mathrm{pH}(\mathrm{p}<0,05)$, os dados sugerem que o tempo de armazenamento foi o fator de maior influência sobre o pH do leite fermentado. Em relação à redução de $\mathrm{pH}$ em função do tempo de armazenamento, isto tem sido, geralmente, atribuído à ação de microrganismos que utilizam componentes do leite fermentado em suas vias metabólicas e produzem compostos que reduzem o pH (Bonczar et al., 2002). Resultados semelhantes foram observados por Warakaulle et al. (2014) ao avaliarem o $\mathrm{pH}$ de leite fermentado ao longo de 21 dias de armazenamento a $4^{\circ} \mathrm{C}$. Em média, o pH das amostras do leite fermentado foi de 4,42, o que é relativamente semelhante aos valores registrados por Aryana et al. (2007) para leite fermentado.

Os dados sugerem que não houve diferença de sinérese entre os tratamentos para os leites fermentados durante o tempo de armazenamento, esta é uma característica de eficiência na retenção do soro pelo leite fermentado. Sabe-se que o desenvolvimento de fatores antimicrobianos pelos leucócitos, aumentados na mastite, poderiam inibir o desenvolvimento da cultura láctea, retardando o processo de fermentação e coagulação do produto (Viotto e Cunha, 2006; Santos, 2015). Porém algumas pesquisas já demonstraram que é possível não haver diferenças na curva de fermentação entre leites com diferentes níveis de CCS (Fernandes et al., 2007; Faria et al., 2016).

Foram observadas diferenças significativas $(P<0,05)$ para umidade e dureza nos queijos produzidos a partir de leite com diferentes níveis de CCS (Tabela 2). Segundo o Ministério da Agricultura, Pecuária e Abastecimento (MAPA), portaria $\mathrm{n}^{\circ}$ 352 (Brasil, 1997), o queijo Minas Frescal é definido como um queijo fresco obtido por coagulação enzimática do leite através de coalho ou outras enzimas coagulantes apropriadas, é considerado um queijo semi-gordo ( $25 \%$ a $44 \%$ de gordura na matéria seca) e de alta umidade (superior a $55 \%$ ). Sendo assim, todos os queijos produzidos estão de acordo com os padrões para o teor de umidade exigida pela legislação (Tabela 2).

No leite com altos valores de CCS, segundo Coelho et al (2014), a passagem dos componentes sólidos da matéria-prima leite para o queijo no processo de coagulação, torna-se dificultada, devido à ação das enzimas e má formação do coágulo. Outros fatores também devem ser considerados, como a dificuldade de acidificação da massa e a perda de nutrientes para o soro na primeira e segunda mexeduras, fatores estes que, associados, conduzem para maior teor de água nos queijos e, consequentemente maiores teores de umidade.

A atividade de água é um parâmetro indicativo da estabilidade dos alimentos, e quando elevada, favorece o desenvolvimento de microrganismos, provocando redução na vida de prateleira (Jay, 2005). Para esta análise, não foram observadas diferenças $(P>0,05)$ entre os tratamentos, embora os teores de umidade tenham apresentado diferença significativa (Tabela 2). 
Tabela 1 - Parâmetros avaliados no leite fermentado e interação do tratamento $\mathrm{x}$ tempo.

\begin{tabular}{|c|c|c|c|c|c|c|c|}
\hline \multicolumn{8}{|c|}{ Tempo (dias) } \\
\hline Item & 1 & 15 & 30 & Média & $\begin{array}{c}\text { Tratamento } x \\
\text { Tempo }\end{array}$ & $\mathbf{P}$ & $\mathbf{R}^{2}$ \\
\hline \multicolumn{8}{|c|}{$\operatorname{CCS}<300$} \\
\hline$L$ & 91,76 & 89,12 & 92,52 & 91,13 & NS & 0,00 & 1,00 \\
\hline$a^{*}$ & 8,37 & - & 8,32 & 8,35 & NS & 0,00 & 1,00 \\
\hline$b^{*}$ & $18,13^{a}$ & $10,69^{b}$ & $16,69^{a}$ & 15,17 & 0,00 & 0,00 & 1,00 \\
\hline $\mathrm{pH}$ & $4,42^{\mathrm{a}}$ & $4,29^{b}$ & $4,32^{b}$ & 4,34 & 0,00 & 0,00 & 0,71 \\
\hline Acidez ( $\left.{ }^{\circ} \mathrm{D}\right)$ & 7,97 & 12,07 & 8,89 & 9,64 & NS & 0,00 & 1,00 \\
\hline Sinérese & $12,34^{a}$ & $6,64^{b}$ & $10,43^{a}$ & 9,80 & 0,01 & 0,03 & 1,00 \\
\hline \multicolumn{8}{|c|}{$\operatorname{CCS} 300-600$} \\
\hline$L$ & 97,72 & 90,74 & 92,46 & 93,64 & NS & 0,00 & 1,00 \\
\hline$a^{*}$ & 8,37 & - & 8,37 & 8,37 & NS & 0,00 & 1,00 \\
\hline$b^{*}$ & $15,04^{b}$ & $9,46^{c}$ & $16,96^{\mathrm{a}}$ & 13,82 & 0,00 & 0,00 & 1,00 \\
\hline $\mathrm{pH}$ & $4,45^{\mathrm{a}}$ & $4,44^{a}$ & $4,39^{b}$ & 4,43 & 0,00 & 0,00 & 0,71 \\
\hline Acidez ( $\left.{ }^{\circ} \mathrm{D}\right)$ & 8,33 & 12,78 & 10,89 & 10,67 & NS & 0,00 & 1,00 \\
\hline Sinérese & $11,84^{a}$ & $10,05^{a}$ & $10,29 a$ & 10,73 & 0,01 & 0,03 & 1,00 \\
\hline \multicolumn{8}{|c|}{$\operatorname{CCS}>600$} \\
\hline $\bar{L}$ & 97,31 & 88,51 & 93,20 & 93,01 & NS & 0,00 & 1,00 \\
\hline$a^{*}$ & 8,53 & - & 8,37 & 8,45 & NS & 0,00 & 1,00 \\
\hline$b^{*}$ & $17,14^{a}$ & $13,95^{b}$ & $18,22^{a}$ & 16,44 & 0,00 & 0,00 & 1,00 \\
\hline $\mathrm{pH}$ & $4,50^{\mathrm{a}}$ & $4,39^{b}$ & $4,42^{b}$ & 4,44 & 0,00 & 0,00 & 0,71 \\
\hline Acidez ( $\left({ }^{\circ} \mathrm{D}\right)$ & 9,07 & 13,82 & 11,25 & 11,38 & NS & 0,00 & 1,00 \\
\hline Sinérese & $7,50^{\mathrm{a}}$ & $8,05^{\mathrm{a}}$ & $9,90^{\mathrm{a}}$ & 8,48 & 0,01 & 0,03 & 1,00 \\
\hline
\end{tabular}

Legenda: Médias seguidas de mesma letra, na linha, não diferem entre si pelo Teste de Tukey a $5 \%$ de probabilidade. P: probabilidade de significância; $\mathrm{R}^{2}$ : coeficiente de determinação.

Os níveis crescentes de CCS influenciaram de forma negativa a dureza dos queijos (Tabela 2), pois durante o processamento de leites contendo alta CCS, ocorreu aumento do tempo de coagulação (média de 1:10 h), diminuição da firmeza do coágulo e perda de sólidos do leite para o soro (Andreatta et al., 2009). Estes dados corroboram com os verificados por Matioli (2000) e Mattiello et al. (2018), que ao avaliarem o rendimento da produção de queijo a partir de leite contendo baixa CCS $(<500.000$ células $/ \mathrm{mL})$ e alta CCS $(>500.000$ células $/ \mathrm{mL})$, observaram menor 
rendimento, menor acidez e maior perda de gordura e proteína solúvel pelo soro em queijos de maior CCS.

Tabela 2 - Características físico-químicas do queijo Minas Frescal produzido com leites contendo diferentes níveis de células somáticas.

\begin{tabular}{cccccc}
\hline \multicolumn{5}{c}{ Níveis de CCS $^{1}$} \\
Item & Baixo & Médio & Alto & EP & $\mathrm{P}$ \\
\hline Umidade (\%) & $60,47^{\mathrm{b}}$ & $62,28^{\mathrm{ab}}$ & $64,83^{\mathrm{a}}$ & 0,739 & 0,03 \\
Dureza (N) & $1,73^{\mathrm{a}}$ & $1,68^{\mathrm{a}}$ & $0,85^{\mathrm{b}}$ & 0,033 & $<0,01$ \\
Atividade de água & $0,99^{\mathrm{a}}$ & $0,98^{\mathrm{a}}$ & $0,99^{\mathrm{a}}$ & 0,004 & 0,15 \\
\hline
\end{tabular}

Legenda: Médias seguidas de mesma letra, na linha, não diferem entre si pelo Teste de Tukey a $5 \%$ de probabilidade. ${ }^{1}$ Baixo $<300.000 \mathrm{cel} / \mathrm{mL}$; Médio: 300.000 a $600.000 \mathrm{cel} / \mathrm{mL}$; Alto $>600.000 \mathrm{cel} / \mathrm{mL}$. EP: erro padrão; P: probabilidade de significância.

Os efeitos sobre a variável $\mathrm{a}^{*}, \mathrm{~b}^{*}$, valor de $\mathrm{pH}$ e acidez, dos tratamentos no queijo Minas Frescal, foram diferentes ao longo dos dias de avaliação (Tabela 3). No $20^{\circ}$ dia e último tempo de avaliação o tratamento com baixa CCS apresentou menor valor para a variável $a^{*}$ (relativa ao verde e vermelho) e maior valor para a variável $\mathrm{b}^{*}$ (relativa ao azul e amarelo), quando comparado aos demais tratamentos, indicando que o queijo Minas Frescal mantém sua coloração mais desejável (mais próximo do amarelo) por mais tempo quando produzido com leite de menor CCS. Aparentemente, estas alterações referentes aos aspectos de coloração observados pelo instrumento de medida foram também detectadas pelos avaliadores, tendo em vista que durante a avaliação sensorial o tratamento com altos níveis de CCS recebeu as menores notas para o parâmetro cor (Tabela 4).

Embora exista semelhança no comportamento do $\mathrm{pH}$ entre todos tratamentos (Tabela 3), observando tendência de redução desta variável durante a vida de prateleira, o menor valor pertence aos queijos produzidos com leite de alta CCS, pois assim como ocorre com o leite fermentado, microrganismos utilizam nutrientes presentes no queijo em suas vias metabólicas e desta forma produzem ácidos orgânicos que reduzem o pH (Bonczar et al., 2002).

Os resultados de $\mathrm{pH}$ também estão em conformidade com os valores de acidez titulável. De modo geral, foi observado aumento nos valores de acidez ao longo do tempo de armazenamento e o tratamento contendo alta CCS, além de apresentar o menor $\mathrm{pH}$, apresentou a maior acidez titulável. Aumentos na acidez titulável podem também ser atribuídos à produção de ácidos durante a fermentação (Bakirci e Kavaz, 2008).

$\mathrm{Na}$ avaliação sensorial não foram observadas diferenças significativas $(P>0,05)$ em função dos diferentes níveis de CCS para o leite fermentado (Tabela 4), sugerindo que para a sua produção, os valores de CCS não influenciaram na aceitação do produto por parte dos consumidores. No entanto, para o queijo Minas Frescal, o produto elaborado a partir do leite contendo alta CCS apresentou os menores $(P<0,05)$ escores médios para todos os atributos avaliados (cor, sabor, textura, aparência e aceitação global) (Tabela 4). 
Tabela 3 - Parâmetros avaliados no queijo Minas Frescal e suas interações do tratamento $\mathrm{x}$ tempo.

\begin{tabular}{|c|c|c|c|c|c|c|c|}
\hline \multirow[b]{2}{*}{ Item } & \multicolumn{3}{|c|}{ Tempo (dias) } & \multirow{2}{*}{ Média } & \multirow{2}{*}{$\begin{array}{c}\text { Tratamento } \times \\
\text { Tempo }\end{array}$} & \multirow{2}{*}{$\mathrm{P}$} & \multirow{2}{*}{$\mathrm{R}^{2}$} \\
\hline & 1 & 10 & 20 & & & & \\
\hline \multicolumn{8}{|c|}{ CCS $<300$} \\
\hline $\mathrm{L}$ & 89,42 & 90,19 & 87,98 & 89,2 & NS & 0,00 & 1,00 \\
\hline$a^{*}$ & $1,89^{a}$ & $1,76^{\mathrm{a}}$ & $1,06^{b}$ & 1,57 & 0,00 & 0,03 & 0,71 \\
\hline$b^{*}$ & $8,86^{\mathrm{b}}$ & $10,40^{\mathrm{a}}$ & $11,56^{\mathrm{a}}$ & 10,27 & 0,02 & 0,00 & 0,97 \\
\hline $\mathrm{pH}$ & $6,73^{\mathrm{ab}}$ & $6,80^{a b}$ & $6,67^{b}$ & 6,73 & 0,00 & 0,00 & 1,00 \\
\hline Acidez ( $\left.{ }^{\circ} \mathrm{D}\right)$ & $0,40^{\mathrm{b}}$ & $0,73^{\mathrm{a}}$ & $0,93^{a}$ & 0,69 & 0,01 & 0,00 & 1,00 \\
\hline \multicolumn{8}{|c|}{ CCS 300-600 } \\
\hline $\mathrm{L}$ & 90,79 & 90,75 & 89,74 & 90,43 & NS & 0,00 & 1,00 \\
\hline$a^{*}$ & $1,86^{\mathrm{a}}$ & $1,59^{b}$ & $1,88^{\mathrm{a}}$ & 1,78 & 0,00 & 0,03 & 0,71 \\
\hline$b^{*}$ & $6,79^{\mathrm{b}}$ & $8,63^{a}$ & $9,56^{a}$ & 8,33 & 0,02 & 0,00 & 0,97 \\
\hline $\mathrm{pH}$ & $6,73^{b}$ & $6,90^{\mathrm{a}}$ & $6,63^{\mathrm{c}}$ & 6,75 & 0,00 & 0,00 & 1,00 \\
\hline Acidez ( $\left.{ }^{\circ} \mathrm{D}\right)$ & $0,40^{\mathrm{a}}$ & $0,53^{\mathrm{ab}}$ & $0,67^{\mathrm{ab}}$ & 0,53 & 0,01 & 0,00 & 1,00 \\
\hline \multicolumn{8}{|c|}{ CCS $>600$} \\
\hline L & 89,54 & 90,78 & 88,53 & 89,62 & NS & 0,00 & 1,00 \\
\hline$a^{*}$ & $1,72^{\mathrm{b}}$ & $1,60^{\mathrm{b}}$ & $2,02^{a}$ & 1,78 & 0,00 & 0,03 & 0,71 \\
\hline$b^{*}$ & $9,62^{\mathrm{a}}$ & $9,95^{\mathrm{a}}$ & $10,18^{a}$ & 9,92 & 0,02 & 0,00 & 0,97 \\
\hline $\mathrm{pH}$ & $6,83^{a}$ & $6,90^{\mathrm{a}}$ & $6,53^{b}$ & 6,75 & 0,00 & 0,00 & 1,00 \\
\hline Acidez ( $\left.{ }^{\circ} \mathrm{D}\right)$ & $0,40^{\mathrm{b}}$ & $0,53^{b}$ & $1,03^{a}$ & 0,65 & 0,01 & 0,00 & 1,00 \\
\hline
\end{tabular}

Legenda: Médias seguidas de mesma letra, na linha, não diferem entre si pelo Teste de Tukey a $5 \%$ de probabilidade. P: probabilidade de significância; $\mathrm{R}^{2}$ : coeficiente de determinação.

Tabela 4 - Escores médios obtidos para a avaliação sensorial de leite fermentado e queijo Minas Frescal produzidos com leites contendo diferentes níveis de células somáticas.

\begin{tabular}{ccccc}
\hline Item & \multicolumn{4}{c}{ Nível de CCS $^{1}$} \\
Baixo & Médio & Alto & Média \\
\hline Leite fermentado & & & & \\
Cor & $8,03^{\mathrm{a}}$ & $7,95^{\mathrm{a}}$ & $8,00^{\mathrm{a}}$ & 7,99 \\
Sabor & $7,78^{\mathrm{a}}$ & $7,70^{\mathrm{a}}$ & $8,05^{\mathrm{a}}$ & 7,84 \\
Textura & $7,40^{\mathrm{a}}$ & $7,10^{\mathrm{a}}$ & $7,73^{\mathrm{a}}$ & 7,41 \\
Aparência & $7,88^{\mathrm{a}}$ & $7,65^{\mathrm{a}}$ & $7,98^{\mathrm{a}}$ & 7,84 \\
Aceitação Global & $7,63^{\mathrm{a}}$ & $7,50^{\mathrm{a}}$ & $7,95^{\mathrm{a}}$ & 7,69 \\
\hline Queijo Minas Frescal & & & & \\
Cor & $7,68^{\mathrm{a}}$ & $7,84^{\mathrm{a}}$ & $7,00^{\mathrm{b}}$ & 7,51 \\
Sabor & $6,94^{\mathrm{a}}$ & $7,18^{\mathrm{a}}$ & $5,58^{\mathrm{b}}$ & 6,57 \\
Textura & $7,32^{\mathrm{a}}$ & $7,50^{\mathrm{a}}$ & $5,38^{\mathrm{b}}$ & 6,73 \\
Aparência & $7,56^{\mathrm{a}}$ & $7,52^{\mathrm{a}}$ & $5,78^{\mathrm{b}}$ & 6.95 \\
Aceitação Global & $7,36^{\mathrm{a}}$ & $7,50^{\mathrm{a}}$ & $5,92^{\mathrm{b}}$ & 6,93 \\
\hline
\end{tabular}

Legenda: ${ }^{1}$ Baixo < $300.000 \mathrm{cel} / \mathrm{mL}$; Médio: 300.000 a $600.000 \mathrm{cel} / \mathrm{mL}$; Alto $>600.000 \mathrm{cel} / \mathrm{mL}$. Médias seguidas de mesma letra, na linha, não diferem entre si pelo Teste de Tukey a $5 \%$ de probabilidade.

Os resultados obtidos para análise sensorial (Tabela 4) indicam que o queijo Minas Frescal produzido a partir do leite com alta CCS apresentou maior rejeição por parte dos provadores, evidenciando os dados observados com relação aos 
maiores teores para umidade e menores de dureza (Tabela 2) influenciando, desta forma, negativamente as notas atribuídas pelos provadores. Resultados semelhantes foram observados por Andreatta et al. (2009) que relataram menor aceitação global do queijo Minas Frescal produzido a partir de leite com alta CCS $(1.053 .000 \mathrm{cel} / \mathrm{mL})$, sugerindo que este é um fator capaz de influenciar negativamente na qualidade sensorial. Na produção de queijos, alta CCS no leite tem sido registrada como determinante em um menor rendimento na fabricação e defeitos na textura, itens estes capazes de inviabilizar a produção e a comercialização do produto (Andreatta et al., 2009; Coelho et al., 2016).

\section{CONCLUSÃO}

$\mathrm{O} \mathrm{pH}$ do leite fermentado foi influenciado pelo tempo de armazenamento e os diferentes níveis de CCS não alteraram a aceitação sensorial do produto. Entretanto, os parâmetros físico-químicos avaliados durante a vida de prateleira do queijo Minas Frescal e a aceitação global foram influenciados negativamente pelo alto nível de CCS (>600.000 cel/mL) do leite, apresentando menor $\mathrm{pH}$ e maior acidez.

\section{NOTA INFORMATIVA}

Número de protocolo de aprovação da pesquisa pelo comitê de ética: 43112815.9.0000.0104

\section{REFERÊNCIAS}

ANDREATTA, E.; FERNANDES, A. M.; SANTOS, M. V.; et al. Quality of Minas Frescal cheese prepared from milk with different somatic cell counts. Pesquisa Agropecuária Brasileira, Pirassununga, v.44, n.3, p.320-326, 2009. Disponível em: $<$ http://www.scielo.br/scielo.php?script=sci arttext\&pid=S0100-

204X2009000300014>. Acesso em: 24/02/2020.

ARYANA, K. J.; PLAUCHE, S.; RAO, R. M.; et al. Fat-Free Plain Yogurt Manufactured with Inulins of Various Chain Lengths and Lactobacillus acidophilus. Journal of Food Science, v.72, n.3, p.79-84, 2007. Disponível em: $<$ https://onlinelibrary.wiley.com/doi/full/10.1111/j.1750-3841.2007.00302.x>. Acesso em: 25/02/2020.

BAKIRCI, I.; KAVAZ, A. An investigation of some properties of banana yogurts made with commercial ABT-2 starter culture during storage. Intenational Journal of Dairy Technology, v.61, n.3, p.270-276, 2008. Disponível em: $<$ https://onlinelibrary.wiley.com/doi/full/10.1111/j.1471-0307.2008.00409.x>. Acesso em: 25/02/2020.

BONCZAR, G.; WSZOLEK, M.; SIUTA, A. The effects of certain factors on the properties of yogurt made from ewe's milk. Food Chemistry, v.79, n.1, p.85-91, $2002 . \quad$ Disponível em: $<$ https://www.sciencedirect.com/science/article/pii/S0308814602001826>. Acesso em: 24/02/2020.

BRASIL. Instrução Normativa n. 76 de 26 de novembro de 2018. Dispõe sobre Regulamento Técnico de Identidade e Qualidade de leite cru refrigerado. Diário 
Oficial da República Federativa do Brasil, Brasília, Seção 1, n.230, p.9, 30 nov. 2018.

BRASIL. Ministério de Agricultura, Pecuária e Abastecimento. Portaria no 352, de 04 de setembro de 1997. Regulamento Técnico de Identidade e Qualidade de queijo Minas Frescal. Diário Oficial da República Federativa do Brasil, 8 set. 1997. Seção 1, Página 19684.

CARVALHO, T.S.; SILVA, M.A.P.; BRASIL, R.B. et al. Qualidade do leite cru refrigerado e obtido atraves da ordenha manual e mecanica. Revista do Instituto de Laticínios Cândido Tostes, v. 68, n. 390, p. 5-11, 2013. Disponível em: <https://rilct.emnuvens.com.br/rilct/article/view/2>. Acesso em: 17/06/2020.

COELHO, K. O.; DA SILVA, A. A.; BRAGA, P. D. C. et al. Efeito do nível de células somáticas sobre o rendimento do queijo prato. PUBVET, v. 6, p. Art. 1352-1356, 2016. Disponível em: <http://www.pubvet.com.br/artigo/3403/efeito-do-niacutevel-deceacutelulas-somaacuteticas-sobre-o-rendimento-do-queijo-prato>. Acesso em: 27/02/2020.

COELHO, K. O.; MESQUITA, A. J.; MACHADO, P. F. et al. Efeito da contagem de células somáticas sobre o rendimento e a composição físico-química do queijo Muçarela. Arquivo Brasileiro de Medicina Veterinária e Zootecnia, v.66, n.4, p.1260-1268, 2014. Disponível em: <http://www.scielo.br/scielo.php?pid=S010209352014000401260\&script=sci arttext>. Acesso em: 25/02/2020.

COSTA H. N.; MOLINA L. R.; LAGE C. F. A. et al. Estimativa das perdas de produção leiteira em vacas mestiças Holandês $x$ Zebu com mastite subclínica baseada em duas metodologias de análise. Arquivo Brasileiro de Medicina Veterinária e Zootecnia, v. 69, n. 3, p. 579-586, 2017. Disponível em: $<$ http://www.scielo.br/scielo.php?pid=S0102-

09352017000300579\&script=sci arttext>. Acesso em: 25/02/2020.

DA SILVA ROBAZZA, W. S.; LONGHI, D. A.; DE ALMEIDA GOMES, G. Avaliação da qualidade de iogurte em função da cultura iniciadora. Higiene Alimentar, v. 25, n. 194/195, 2011. Disponível em: $<$ https://www.researchgate.net/profile/Daniel Longhi/publication/299866682 Avaliac ao da Qualidade de logurte em funcao da Cultura Iniciadora/links/57f4df1008ae 886b897f3e3c/Avaliacao-da-Qualidade-de-logurte-em-funcao-da-CulturaIniciadora.pdf>. Acesso em: 15/06/2020.

DE VLIEGHER, S.; FOX, L. K.; PIEPERS, S. et al. Invited review: Mastitis in dairy heifers: Nature of the disease, potential impact, prevention, and control. Journal of Dairy Science, v.95, n.3, p.1025-1040, 2012. Disponível em: <https://www.sciencedirect.com/science/article/pii/S0022030212000628>. Acesso em: 24/02/2020.

DEMEU F. A.; LOPES M. A.; COSTA G. M. et al. Efeito da produtividade diária de leite no impacto econômico da mastite em rebanhos bovinos. Boletim de Indústria Animal, v. 73, n. 1, p. 53-61, 2016. Disponível em: $<$ http://iz.agricultura.sp.gov.br/bia/index.php/bia/article/view/496>. Acesso em: 01/03/2020. 
FARIA, A. P. A.; PENNA, C. F. D. A. M.; PINTO, M. S. et al. (2016). Influência do leite com elevada contagem de células somáticas sobre características físicoquímicas e processo de fermentação de iogurte. Ciência Animal Brasileira. Disponível em: <file:///C:/Users/Master/Downloads/44773-Texto\%20do\%20artigo272855-2-10-20200222.pdf>. Acesso em: 13/06/2020.

FERNANDES, A. M.; OLIVEIRA, C. A. F.; LIMA, C. G. Effects of somatic cell counts in milk on physical and chemical characteristics of yogurt. International Dairy Journal. $\quad 2007 ; \quad 17: 111-115 . \quad$ Disponível em: $<$ https://www.sciencedirect.com/science/article/pii/S0958694606000458?casa token =yXNFNLBUTPYAAAAA:-

Eifbh20bgZuLe8GtUH7HNSqWW6XkISuyrK4IXZEA3gPKJT9HZIPp7KqJjyPIh20LAAI ma879Q>. Acesso em: 13/06/2020.

INSTITUTO ADOLFO LUTZ. Normas analíticas. Métodos químicos e físicos para análises de alimentos. $4^{\circ}$ ed. São Paulo: Instituto Adolfo Lutz, 2008. 1020 p.

JAY, J. M. Microbiologia de alimentos. 6.ed. Tradução: Eduardo César Tondo. Porto Alegre: Artmed, 2005. p. 712.

MACHADO, P. F.; PEREIRA, A. R.; SILVA, L. F. P. et al. Células somáticas no leite em rebanhos brasileiros. Scientia Agrícola, v. 57, n. 2, p. 359-361, 2000. Disponível em: $\quad<h t$ tps://www.scielo.br/scielo.php?pid=S010390162000000200026\&script=sci arttext\&tlng=pt>. Acesso em: 17/06/2020.

MAGALHÃES, H. R.; FARO, L. E.; CARDOSO, V. L. et al. Influência de fatores de ambiente sobre a contagem de células somáticas e sua relação com perdas na produção de leite de vacas da raça Holandesa. Revista Brasileira de Zootecnia, v.35, n.2, p.415-421. 2006. Disponível em: $<$ http://www.scielo.br/scielo.php?pid=S1516-

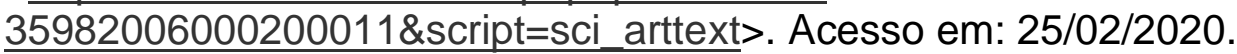

MATIOLI, G. P. Influência do leite proveniente de vacas mastíticas no rendimento de queijo Minas Frescal. 2000. 55 f. Dissertação (Mestrado em Ciência de Alimentos) - Universidade Federal de Lavras, Lavras, 2000.

MATTIELLO, C. A.; SILVEIRA, S. M.; CARLI, F.; et al. Rendimento industrial, eificência de fabricação e características físico-químicas de queijo colonial produzido de leite com dois níveis de células somáticas. Arquivo Brasileiro de Medicina Veterinária e Zootecnia, v.70, n.6, p.1916-1924. 2018. Disponível em: $<$ http://www.scielo.br/scielo.php?pid=S0102-

09352018000601916\&script=sci arttext>. Acesso em: 01/03/2020.

MESQUITA, A. A.; BORGES, J.; PINTO, S. M. et al. Contagem bacteriana total e contagem de células somáticas como indicadores de perdas de produção de leite. PUBVET, v. 12, p. 131, 2018. Disponível em: $<$ http://www.pubvet.com.br/artigo/4762/contagem-bacteriana-total-e-contagem-deceacutelulas-somaacuteticas-como-indicadores-de-perdas-de-produccedilatildeo-deleite>. Acesso em: 25/02/2020. 
OLIVEIRA, C. D., DE PAULO, F. J., DE OLIVEIRA, J. C. C. et al. Caracterização físico-química do iogurte tipo sundae sabor jabuticaba/Physical-chemical characterization of yogurt type sundae jabuticaba flavor. Brazilian Journal of Development, v. 5, n. 6, p. 5091-5097, 2019. Disponível em: $<$ http://www.brazilianjournals.com/index.php/BRJD/article/view/1700>. Acesso em: $15 / 06 / 2020$.

RAWSON, H. L.; MARSHALL, V. M. Effect of 'ropy' strains of Lactobacillus delbrueckii ssp. bulgaricus and Streptococcus thermophilus on rheology of stirred yogurt. International Journal of Food Science \& Technology, v.32, n.3, p.213220, 1997. Disponível em: <https://onlinelibrary.wiley.com/doi/abs/10.1046/j.13652621.1997.00395.x>. Acesso em: 25/02/2020.

ROBITAILLE, G.; TREMBLAY, A.; MOINEAU, S. et al. Fat-free yogurt made using a galactose-positive exopolysaccharide-producing recombinant strain of Streptococcus thermophilus. Journal of Dairy Science, v.92, n.2, p.477-482, 2009. Disponível em: $<$ https://www.sciencedirect.com/science/article/pii/S0022030209703510>. Acesso em: 25/02/2020.

SAMARŽIJA, D.; ZAMBERLIN, Š.; POGAČIĆ, T. Psychrotrophic bacteria and their negative effects on milk and dairy products quality. Mljekarstvo: časopis za unaprjeđenje proizvodnje i prerade mlijeka, v. 62, n. 2, p. 77-95, 2012. Disponível em: <https://hrcak.srce.hr/83325>. Acesso em: 24/02/2020.

SANTOS M. V. Alto nível de CCS prejudica leite e derivados. Revista Mundo do Leite. 2015. Disponível em: <http://www.portaldbo.com.br/mundo-doleite/artigos/alto-nivelde-ccs-prejudica-leite-e-derivados/13465>. Acesso em: 13/06/2020.

SILVA M. V. M.; NOGUEIRA J. L.; PASSOS C. C. et al. Ferreira A.O. \& Ambrósio C.E. 2010. A mastite interferindo no padrão de qualidade do leite: uma preocupação necessária. Revista Científica Eletrônica de Medicina Veterinária, v. 3, n. 14, p. 1-10, 2010.2 Disponível em: $<$ http://www.faef.revista.inf.br/imagens arquivos/arquivos destaque/ExJ4wrjaJDV2x TJ 2013-6-25-15-12-5.pdf >. Acesso em: 24/02/2020.

SILVA, J. C.; ANTUNES, R. C. Efeito do tipo de ordenha e do ambiente sobre a qualidade do leite cru com base na contagem de células somáticas. Ciência Animal Brasileira, v. 19, 2018. Disponível em: <http://www.scielo.br/scielo.php?pid=S1809$68912018000100602 \&$ script=sci arttext\&tlng=pt>. Acesso em: 01/03/2020.

VIOTTO, W. H.; CUNHA, C. R. Teor de sólidos do leite e rendimento industrial. In: Albenones JM, Dürr JW, Coelho KO. Perspectivas e avanços da qualidade do leite no Brasil. 1nd ed. Goiânia: Talento Gráfica e Editora; 2006. p. 241-258.

WARAKAULLE, S. T. S. K.; WEERATHILAKE, W. A. D. V.; ABEYNAYAKE, N. R. Production and Evaluation of Set type Yogurt Incorporated with Water melon (Citrallus lanatus) International Journal of Scientific and Research Publications, Sri Lanka, v.4, n.10, p.1-4, 2014. Disponível em: $<$ http://citeseerx.ist.psu.edu/viewdoc/download?doi=10.1.1.657.1513\&rep=rep1\&type $=$ pdf\#page $=694$ 